\title{
PENGARUH LINGKUNGAN KERJA TERHADAP KEPUASAN KERJA PERAWAT DI RSUD MASSENREMPULU ENREKANG
}

\section{THE EFFECT OF WORK ENVIRONMENT TO NURSE JOB SATISFACTION AT MASSENREMPULU HOSPITAL ENREKANG 2018}

\author{
Andi Jamalina ${ }^{1}$, A.Indahwaty Sidin ${ }^{1}$, Anwar Mallongi ${ }^{2}$ \\ ${ }^{1}$ Bagian Administrasi Rumah Sakit, Fakultas Kesehatan Masyarakat, Universitas \\ Hasanuddin, Makassar \\ ${ }^{2}$ Bagian Kesehatan Lingkungan, Fakultas Kesehatan Masyarakat, Universitas Hasanuddin, \\ Makassar
}

\author{
Alamat Korespondensi: Andi Jamalina, S.Kep, Ns, Fakultas Kesehatan Masyarakat \\ Universitas Hasanuddin, Makassar, 90245 HP: 081342526995 \\ Email: anjhalinha@gmail.com
}

\begin{abstract}
Abstrak
Kepuasan kerja perawat sangat di butuhkan bagi perawat agar meningkatkan pelayanan kesehatan. Penelitian ini bertujuan mengalisis pengaruh lingkungan kerja terhadap kepuasan kerja perawat di RSUD Massenrempulu Enrekang Tahun 2017. Penelitian ini merupakan jenis penelitian kuantitatif. Rancangan yang digunakan adalah observasional analitik dengan pendekatan cross sectional study. Sampel sebanyak 94 orang yang ditentukan dengan teknik Accidental sampling. Data dianalisis secara kuantitatif dengan menggunakan analisis statistik melalui uji regresi linier sederhana dan dilanjutkan dengan uji regresi berganda. Hasil penelitian menunjukkan bahwa kepemimpinan berpengaruh signifikan terhadap kepuasan kerja perawat. Pengaruh yang positif dan signifikan ditunjukkan oleh nilai signifikansi sebesar $0,001<0,005$ nilai $\alpha$ serta nilai $\mathrm{t}$ hitung $=19,692>\mathrm{t}$ tabel $=1,960$. kolaborasi perawat-dokter tidak berpengaruh signifikan terhadap kepuasan kerja perawat. Pengaruh insignifikan ditunjukkan oleh nilai signifikansi sebesar $0,245>0,005$ nilai $\alpha$ serta nilai $\mathrm{t}$ hitung $=1,170<\mathrm{t}$ tabel $=1,960$. Keikutsertaan dalam pengambilan keputusan berpengaruh signifikan terhadap kepuasan kerja perawat . Pengaruh yang positif dan signifikan ditunjukkan oleh nilai $\mathrm{t}$ hitung $=1,990>\mathrm{t}$ tabel $=1,960$. Dan variabel yang paling berpengaruh adalah kepemimpinana dengan nilai $\mathrm{p}=0.000<0.05$. kesimpulan dari hasil penelitian ini adalah lingkungan kerja berpengaruh signifikan terhadap kepuasan kerja perawat ditunjukkan oleh nilai signifikansi sebesar $0,036<0,005$.
\end{abstract}

Kata kunci : Nurse-work environment, job satisfaction Abstract

Nursing job satisfaction is needed for nurses to improve health services. This study aims to analyze the influence of work environment on nurse job satisfaction at Massenrempulu Hospital Enrekan in 2017. This research was a quantitative research type. The design used was observational analytic with cross sectional approach. A sample of 94 people is determined by Accidental sampling technique. Data analyzed quantitatively by using statistical analysis simple linear regression and then multiple regression test. The results showed that leadership had a significant effect on nurse job satisfaction. Positive and significant influence is indicated by the significance value of $0.001<0.005 \alpha$ value and $t$ value $=19.692>t$ table $=1.960$. nurse-physician collaboration has no significant effect on nurse's job satisfaction. Insignificant influence is indicated by the significance value of $0.245>0.005 \alpha$ value and the value of $t$ arithmetic $=1,170<t$ table $=1.960$. Participation in decision making has a significant effect on nurse job satisfaction. Positive and significant influence is indicated by the value of $t$ arithmetic $=1.990>t$ table $=1.960$. And the most influential variable is the leadership with the value $p=0.000$ $<0.05$. conclusion from result of this research is work environment have significant effect to nurse job satisfaction indicated by significance value equal to 0,036 <0,005 


\section{PENDAHULUAN}

Kepuasan kerja merupakan faktor penting dalam organisasi pelayananan kesehatan, khususnya dibidang keperawatan (George \& Keren,2005). Kepuasan kerja perawat sangat di butuhkan bagi perawat agar meningkatkan pelayanan kesehatan. Kepuasan kerja adalah keadaan emosional yang menyenangkan atau positif, yang dihasilkan penilaian pekerjaan dari seseorang atau pengalaman kerja (Persefoni et al. 2010) dalam penelitian Nemmaniwar \& Deshpande, (2016).

Amerika Serikat selama 30 tahun terakhir umumnya mengindikasikan lebih banyak pekerja yang puas dengan pekerjaannya dibanding dengan yang tidak. Riset terkini menemukan bahwa tingkat kepuasan kerja rata-rata secara konsisten tinggi dari tahun 1977-2006. Tetapi data terkini menunjukkan sebuah penurunan dramatis dalam tingkat kepuasan kerja rata-rata selama krisis ekonomi yang dimulai di akhir tahun 2007, sangat turun sampai hanya sekitar setengah pekerja yang dilaporkan puas dengan pekerjaannya saat ini (Robbin \& Judge, 2017).

Penelitian Aiken et al. (2001) menemukan ketidakpuasan kerja di kalangan perawat di Amerika Serikat (41\%), Skotlandia (38\%), Inggris (36\%), Kanada (33\%) dan Jerman (17\%). Di Indonesia, Kartika (2012) di Bekasi diketahui bahwa kepuasan kerja perawat rendah sebesar 92,96\%, Andi Kinarkas Argapati (2013) di Makassar menemukan bahwa kepuasan kerja perawat di ruang rawat inap adalah 60,8\%, sedangkan Oldemar (2015) di Pekanbaru menemukan kepuasan kerja perawat rendah sebesar 49,6\%.

Dalam penelitian Gunnasdottir, et al.(2009) dalam Liu et al. (2012) mengenai lingkungan kerja, kepuasan kerja, kelelahan, dan kualitas perawatan, lingkungan kerja ditemukan sebagai prediktor kepuasan kerja. Banyak penelitian telah mendokumentasikan hubungan antara kualitas lingkungan kerja perawat terhadap kepuasan perawat dan kepuasan pasien serta kualitas perawatan (Laschinger\&Finegan 2005, Aiken et al. 2008, Friese et al. 2008 dalam Liu et al. 2012).Data dari sampel rumah sakit internasional dari negara-negara Barat mengindikasikan bahwa perawat yang bekerja di rumah sakit denganl ingkungan yang jelek lebih mungkin melaporkan ketidakpuasan dan kelelahan yang lebih tinggi (Aiken et al. 2002 dalam Liu et al. 2012).

Studi Atencio et al. (2003) dalam Liu et al., (2012) menunjukkan bahwa lingkungan kerja yang positif dapat meningkatkan kepuasan kerja, mempertahankan perawat dan mengurangi omset. Studi oleh Lynn dan Redman (2005) dan Kreitzer et al. (1997) dalam Liu et al. 2012) juga menemukan bahwa lingkungan kerja yang tidak sehat menyebabkan ketidakpuasan kerja dan kelelahan di kalangan perawat.

Menurut sebuah penelitian di kalangan perawat unit perawatan intensif (ICU), Stone et al.(2007) dalam Aiken et al. (2002) menyimpulkan bahwa menciptakan iklim organisasi yang positif dapat mengurangi niat untuk pergi.

Sejumlah penelitian menunjukkan bahwa perawat tidak puas dengan lingkungan kerja mereka (Aiken, 2002). Lingkungan kerja mencakup lima komponen lingkungan praktik profesional yang terdiri Kepemimpinan yang kuat (Strong Leadership), Kolaborasi PerawatDokter (Nurse-Physician Collaboration), Keterlibatan dalam pengambilan keputusan Kebijakan (Policy Involment), Kecukupan Tenaga (Staffing Adequate), dan Model Praktik Keperawatan (Nursing Model Of Care) ((Laschinger \& Leiter, 2006). Penelitian keperawatan telah menunjukkan efek dari komponen lingkungan kerja terhadap kinerja perawat dan kualitas perawatan pasien (Gikopoulou et al. 2014).

Dalam penelitian yang dilakukan oleh (Myriam Breau, 2014); Choi, Cheung, \& Pang, 2013); (Manojlovich \& Laschinger, 2008), menemukan bahwa dimensi lingkungan kerja yang 
mempengaruhi kepuasan kerja perawat adalah kepemimpinan dan dukungan manager keperawatan.Dalam penelitian Gikopoulou, Tsironi, Lazakidou, Moisoglou, \& Prezerakos, (2014) menemukan pengaruh positif antara kolaborasi perawat-dokter terhadap kemungkinan terjadi kesalahan, dan mengurangi kelelahan sehingga membawa pengaruh positif pada kepuasan kerja perawat.

Dari data Kepuasan kerja perawat di RSUD Massenrempulu Enrekang didapatkan kepuasan kerja sebesar 59,9\%. Hal ini menunjukkan rendahnya tingkat kepuasan kerja perawat di RSUD Massenrempulu Enrekang dibandingkan dengan standar kepuasan kerja provider BPJS $80 \%$ dipersyaratkan sebagai kepuasan kerja. Penelitian ini bertujuan untuk menganalisis pengaruh lingkungan kerja terhadap kepuasan kerja perawat di RSUD Massenrempulu Enrekang.

\section{BAHAN DAN METODE}

\section{Lokasi dan Rancangan penelitian}

Penelitian ini dilakukan di RSUD Massenrempulu Enrekang, Sulawesi Selatan. Jenis penelitian yang digunakan adalah observational analitik dengan menggunakan desain cross sectional study.

\section{Populasi dan sampel}

Populasi adalah seluruh perawat pelaksana di Instalasi Rawat Inap RSUD Massenrempulu Enrekang. Populasi sebanyak 124 perawat dan sampel sebanyak 94 perawat dengan taraf kesalahan 5\% yang dipilih secara accidental sampling yaitu pengambilan sampel yang dilakukan dengan mengambil kasus atau responden yang kebetulan ada atau tersedia disuatu tempat sesuai dengan konteks penelitian. Sampel telah memenuhi criteria inklusi yaitu telah bekerja maksimal 1 tahun, kooperatif dan bersedia menjadi responden dan kriteria ekskusi perawat pelaksana yang sedang cuti atau sakit, dan perawat yang sedang mengikuti program tugas belajar.

\section{Metode pengumpulan data}

Data primer yaitu data yang diambil oleh peneliti secara langsung dari sumbernya yang diperoleh melalui teknik pengumpulan data dengan menggunakan kuesioner. Kuesioner yang digunakan adalah kuesioner Lingkungan Kerja Perawat, dan Kepuasan Kerja Perawat.. Adapun kuesioner Lingkungan Keja Perawat diadaptasi dari kuesioner yang dibuat oleh Lake (2002) yang disebut Practice Environment Scale and Nursing Work Index (PES-NWI), yang terdiri dari 6 item pernyataan. Sementara untuk mengukur Kepuasan Kerja Perawat menggunakan Index Work Satisfaction (IWS) diadaptasi dari Stamps (1997) dan diterjemahkan ke dalam Bahasa Indonesia yang terdiri dari 7 item pernyataan

\section{Analisis data}

Analisis data menggunakan program SPSS. Analisis data yang dilakukan untuk mencari ada tidaknya pengaruh variable lingkungan kerja terhadap kepuasan kerja perawat menggunakan uji regresi linear sederhana dengan menggunakan derajat kepercayaan $\alpha=0,05$. Dan untuk menentukan pengaruh secara simultan variable independen yaitu kepemimpinan yang kuat, kolaborasi perawat-dokter, keikutsertaan dalam pengambilan keputusan terhadap variable dependen yaitu kepuasan kerja perawat. Menggunakan uji regresi linear berganda

\section{HASIL PENELITIAN \\ Karakteristik sampel}

Hasil analisis menggambarkan distribusi karakteristik responden berdasarkan umur, jenis kelamin, masa kerja, penghasilan, jabatan,tingkat pendidikan, dan unit kerja. Berdasarkanjenis kelamin, responden yang berjenis kelamin laki-laki sebanyak19 responden $(20,2 \%)$ sedangkan jenis kelamin perempuan sebanyak 75 responden $(79,8 \%)$. Hal ini menunjukkan bahwa sebagian besar dari responden berjenis kelamin perempuan. Dilihat dari umur, paling banyak responden dalam kelompok umur $<35$ tahun berjumlah 87 
responden $(92,6 \%)$, sedangkan paling sedikit dalam kelompok umur $\geq 35$ tahun berjumlah 7 responden $(7,4 \%)$. Hal ini menunjukkan bahwa sebagian besar responden berada pada kelompok umur $<35$ tahun. Berdasarkan tingkat pendidikan, paling banyak responden merupakan lulusan S1+Profesi Keperawatan berjumlah 35 responden $(37,2 \%)$, sedangkan paling sedikit merupakan lulusan DIII Keperawatan berjumlah 29 responden $(30,9 \%)$. Hal ini menunjukkan bahwa sebagian besar responden merupakan lulusan $\mathrm{S} 1+$ Profesi Keperawatan. Dilihat dari masa kerja, paling banyak responden berada pada masa kerja $\geq 3$ tahun berjumlah 89 responden $(94,7 \%)$, sedangkan paling sedikit pada masa kerja $<3$ tahun. Hal ini menunjukkan bahwa sebagian besar responden memiliki masa kerja $\geq 3$ tahun. Selain itu, distribusi frekuensi responden berdasarkan unit kerja secara proporsif dengan jumlah responden yang terbesar yaitu berasal ruang rawat inap interna utara dan interna selatan sebanyak 17 responden ( $18,1 \%)$ sedangkan yang terkecil adalah ruang $\mathrm{OK}$ sebanyak 5 responden (5,3\%).

\section{Analisis Deskriptif}

Berdasarkan hasil analisis yang diperoleh dapat diketetahui bahwa dari 94 responden, variabel kepemimpinan terdapat 41 responden $(43,6 \%)$ dengan kategori baik dan sebanyak 53 responden (56,4\%) dengan kategori kurang baik. Variabel Kolaborasi perawat-dokter terdapat 62 responden $(66,0 \%)$ dengan kategori baik dan sebanyak 32 responden (34,0\%) dengan kategori kurang baik. Variabel Keikutsertaan alam pengambilan keputusan terdapat 68 responden $(72,3 \%)$ dengan kategori baik dan sebanyak 26 responden $(27,7 \%)$ dengan kategori kurang baik. Untuk kepuasan kerja terdapat 53 responden $(56,4 \%)$ dengan kategori puas dan sebanyak 41 responden $(43,6 \%)$ dengan kategori kurang puas.

\section{Analisis Bivariat}

Hasil penelitian pada tabel 1 menunjukkan bahwa ada pengaruh yang signifikan lingkungan kerja terhadap kepuasan kerja di RSUD Massenrempulu Enrekang dengan masing-masing nilai signifikansi $(\mathrm{p}=0,036)$. Ada pengaruh yang signifikan kepemimpinan terhadap kepuasan kerja di RSUD Massenrempulu Enrekang dengan masing-masing nilai signifikansi $(p=0,001)$. Kemudian tidak ada pengaruh yang signifikan pada kolaborasi perawat-dokter terhadap kepuasan kerja di RSUD Massenrempulu Enrekang $(\mathrm{p}=0.245)$. Ada pengaruh yang signifikan keikutsertaan dalam pengambilan keputusan terhadap kepuasan kerja di RSUD Massenrempulu Enrekang dengan masing-masing nilai signifikansi $(\mathrm{t}$ hitung $=1,990$ ).

\section{Analisis Multivariat}

Hasil penelitian pada Tabel 2 menunjukkan bahwa variabel independen yang paling dominan dan signifikan berpengaruh terhadap variabel kepuasan kerja di RSUD Massenrempulu Enrekang adalah variabel Kepemimpinan (B1) = 0,890 dengan $\mathrm{p}=0.001<0,05$.

Tabel 1.Pengaruh lingkungan kerja terhadap kepuasan kerja

\begin{tabular}{llrrrrr}
\hline \multirow{2}{*}{ Model } & $\begin{array}{c}\text { Sum of } \\
\text { Squares }\end{array}$ & df & $\begin{array}{c}\text { Mean } \\
\text { Square }\end{array}$ & F & Sig. \\
\hline \multirow{2}{*}{1} & Regression & 48,318 & 1 & 48,318 & 3,960 &, $050^{\mathrm{b}}$ \\
\cline { 2 - 7 } & Residual & 1122,586 & 92 & 12,202 & & \\
\cline { 2 - 6 } & Total & 1170,904 & 93 & & & \\
\hline
\end{tabular}

Tabel 2. Pengaruh lingkungan kerja secara simultan terhadap kepuasan kerja

\begin{tabular}{lccccc}
\hline Model & $\begin{array}{c}\text { Unstandardized } \\
\text { Coefficients }\end{array}$ & $\begin{array}{c}\text { Standardized } \\
\text { Coefficients }\end{array}$ & t & Sig. \\
\cline { 2 - 5 } & $\mathrm{B}$ & $\begin{array}{c}\text { Std. } \\
\text { Error }\end{array}$ & Beta & & \\
\hline 1 (Constant) & 15,113 & 1,511 & & 10,005 &, 000 \\
\hline Keikutsertaan & .549 &, 276 & .203 & 1,990 &, 050 \\
\hline
\end{tabular}

\section{PEMBAHASAN}

Dalam penelitian ini menunjukkan bahwa Lingkungan kerja berpengaruh signifikan terhadap kepuasan kerja perawat berarti bahwa semakin baik lingkungan kerja di RSUD Massenrempulu Enrekang maka semakin tinggi pula kepuasan kerja perawat di RSUD Massenrempulu Enrekang. 
Hasil penelitian ini sejalan dengan penelitian dari Studi Atencio et al. (2003) menunjukkan bahwa lingkungan kerja yang positif dapat meningkatkan kepuasan kerja. Dan variabel yang paling berpengaruh adalah kepemimpinan. Demikian halnya dengan penelitian yang dilakukan oleh Myriam Breau, (2014); Choi, Cheung, \& Pang, (2013); Manojlovich \& Laschinger, (2008), menemukan bahwa dimensi lingkungan kerja yang mempengaruhi kepuasan kerja perawat adalah kepemimpinan dan dukungan manager keperawatan.

Hasil penelitian ini menunjukkan bahwa kepemimpinan manager keperawatan tingkat menegah dalam hal ini adalah kepala ruangan masih tergolong lemah. Adapun indikator yang paling rendah adalah mengakui kontribusi staf, hal ini dikarenakan perawat yang bekerja tidak pernah mendapatkan pujian dari manager keperawatan mereka sehingga merasa tidak diakui kontribusinya dalam pekerjaan mereka.

Dalam penelitian yang dilakukan oleh (Myriam Breau, 2014); (Choi, Cheung, \& Pang, 2013); (Manojlovich \& Laschinger, 2008), menemukan bahwa dimensi lingkungan kerja yang mempengaruhi kepuasan kerja perawat adalah kepemimpinan dan dukungan manager keperawatan. Kepemimpinan yang kuat dapat ditingkatkan melalui aspek yang dapat membangunnya yaitu mengakui kontribusi staf, kesempatan berkumpul dengan staf, dan memberikan dukungan staf. Menurut DeGieter et al.( 2010 ) pujian dan pengakuan atas pekerjaan yang dilakukan dengan baik dan rasa hormat manajer berkontribusi pada kepuasan kerja perawat.

Hasil penelitian ini menjelaskan bahwa persepsi perawat tentang variabel Kolaborasi perawat-dokter terhadap lingkungan kerja perawat di RSUD Massenrempulu berada dalam kondisi baik sebesar $67,9 \%$ dan variabel insignifikansi tehadap kepuasan kerja perawat. Untuk menyempurnakan variabel ini, sesuai dengan pernyataan pada kuisioner yaitu $\begin{array}{llll}\text { sebanyak } 41 \text { responden } & (67,9 \%)\end{array}$ menyatakan bahwa pada saat dokter melakukan visite perawat segera mendampingi dan melaksanakan instruksi saat DPJP melakukan visite.

Hasil penelian ini sejalan dengan hasil penelitian Zangaro\&Soeken dalam Liu et al. (2012), yang mengatakan bahwa kolaborasi dan otomasi perawat yang positif terkait dengan kepuasan kerja perawat, peluang untuk pertumbuhan dan promosi pribadi.

Keikutsertaan dalam pengambilan keputusan berpengaruh signifikan berarti bahwa semakin baik keikutsertaan dalam pengambilan keputusan maka semakin tinggi pula kepuasan kerja perawat di RSUD Massenrempulu Enrekang.

Hasil penelitian ini ditemukan bahwa kerjasama staf dan komunikasi efektif merupakan aspek yang dapat membangun kepuasan kerja perawat dalam hal keikutsertaan dalam pengambilan keputusan. Dari kedua indikator tersebut dapat diketahui bahwa indikator kerjasama staf paling besar memberikan kontribusi terhadap kepuasan kerja perawat. Adapun indikator yang paling rendah adalah komunikasi efektif, hal ini dikarenakan komunikasi yang terjadi belum efektif dimana keluhan perawat terkait perawatan pasien sebatas mendengarkan keluhan mereka, tidak ada media komunikasi yang tersedia dan kurang mendapat informasi terbaru dari hasil pertemuan dari pihak managemen.

Hal ini sejalan dengan sebuah penelitian yang dilakukan oleh Mohammad Arab et al . (2008) dalam Asadi F. et al. (2008) di seluruh rumah sakit umum dan pendidikan di universitas kedokteran Universitas Teheran, mereka menyimpulkan bahwa partisipasi perawat dalam merencanakan prosedur kualitatif perawatan pasien dapat menurunkan depresi professional mereka (Asadi F. et al. 2008).

Keikutsertaan perawat dalam pengambilan keputusan di RSUD Massenrempulu masih berada pada kondisi baik (sebesar 72,3\%) hal ini dapat dilihat 
dari sekitar 22,3\% dari jumlah 94 responden yang merasa kepala ruangan memiliki kerjasama staf dengan memberikan kesempatan kepada stafnya untuk berpartisipasi dalam menetapkan kebijakan dan prosedur di unit kerja, namun demikian masih terdapat sekitar 3 responden $(3,2 \%)$ menilai kerja sama dalam menentukan kebijakan dan prosedur di unit kerjanya tidak baik.. Hal ini sejalan dengan penelitian yang dilakukan oleh Maryam Zaimi pour et al. (2004) dalam (Aiken et al. 2001) di rumah sakit pendidikan di universitas Teheran, mereka menemukan bahwa latar belakang perawa tprofesional menunjukkan tingkat keterampilan dan pengetahuan mereka yang dapat diterima yang membantu manajer untuk meningkatkan motivasi dan kepuasan kerja mereka dengan cara bekerjasama. kebijakan, kerja kelompok dan komunikasi (Pond WK, 2002).

Keikutsertaan dalam pengambilan keputusan dilandasi oleh komunikasi yang efektif antara kepala ruangan dengan stafnya, perawat di Instalasi RSUD Massenrempulu masih berada pada kondisi komunkasi yang masih kurang baik. Hal ini disebabkan kepala ruangan sebatas mendengarkan keluhan dari staf perawat belum sampai kepada tahap menyediakan fasilitas untuk berkomunikasi lewat alat komunikasi seperti sosial media whatsapp atau sejenisnya.

\section{KESIMPULAN DAN SARAN}

Kami menyimpulkan bahwa dari 3 variabel lingkungan kerja, ada satu variabel yang tidak berpengaruh terhadap kepuasan kerja perawat di RSUD Massenrempulu Enrekang yaitu Kolaborasi Perawat-Dokter. Dikarenakan factor individu perawat itu sendiri maupun factor lingkungan, serta adanya kerjasama yang baik antara dokter dan perawat. Pihak RSUD Massenrempulu perlu melakukan identifikasi dan pengelolaan yang cermat terhadap petunjuk dalam lingkungan kerja yang mempengaruhi kepuasan kerja perawat secara berkala agar dapat selalu mengetahui harapan, keinginan dan kebutuhan perawat dan dapat mengelola espektasi perawat dengan lebih baik.

\section{UCAPAN TERIMA KASIH}

Penulis mengucapkan terima kasih kepada para perawat yang sudah bersedia menjadi responden dalam penelitian ini. Juga kepada pembimbing dan penguji serta rekan-rekan seperjuangan yang telah membantu penulis dalam mengumpulkan sampel untuk dijadikan responden penelitian. Dan semua pihak yang telah membantu hingga penelitian ini selesai dilaksanakan.

\section{DAFTAR PUSTAKA}

Aiken, L. H., Clarke, S. P., Sloane, D. M., Sochalski, J. A., Busse, R., Clarke, H., ... Shamian, J. (2001). Nurses' reports on hospital care in five countries. Health Affairs, 20(3), 4353.

http://doi.org/10.1377/hlthaff.20.3.43

Aiken, L. H. (2002). Hospital Nurse Staffing and Patient Mortality, Nurse Burnout, and Job Dissatisfaction. Jama, 288(16), 1987. http://doi.org/10.1001/jama.288.16.19 87

Asadi F. Fadakar, Z. Khosnodifar, S. M. Hashemi, and G. Hosseininia, A. (2008). Personal Characteristics Affecting Agricultural Extension Workers' Job Satisfaction Level. Journal of Social Sciences, 4(4), 246250.

Choi, S. P. P., Cheung, K., \& Pang, S. M. C. (2013). Attributes of nursing work environment as predictors of registered nurses' job satisfaction and intention to leave. Journal of Nursing Management, 21(3), 429-439. http://doi.org/10.1111/j.13652834.2012.01415.x

Gikopoulou, D., Tsironi, M., Lazakidou, A., Moisoglou, I., \& Prezerakos, P. (2014). The Assessment Of Nurses' Work Environment: The Case of a Greek General Hospital. International Journal of Caring Sciences, 7(1), 269-276. Retrieved from 
www.internationaljournalofcaringscie nces.org

Lake, E. T. (2002). Development of the practice environment scale of the nursing work index. Research in Nursing and Health, 25(3), 176188.http://doi.org/10.1002/nur.10032

Laschinger, H. S. K., \& Leiter, M. P. (2006). The impact of nursing work environments on patient safety outcomes: The mediating role of burnout engagement. Journal of Nursing Administration, 36(5), 259267.

Liu, K., You, L. M., Chen, S. X., Hao, Y. T., Zhu, X. W., Zhang, L. F., Aiken, L. H. (2012). The relationship between hospital work environment and nurse outcomes in Guangdong, China: A nurse questionnaire survey. Journal of Clinical Nursing, 21(9-10), 14761485. http://doi.org/10.1111/j.13652702.2011.03991.x

Manojlovich, M., \& Laschinger, H. K. S. (2008). Application of the Nursing Worklife Model to the ICU Setting. Critical Care Nursing Clinics of North America, 20(4), 481-487. http://doi.org/10.1016/j.ccell.2008.08. 004

Nemmaniwar, A. G., \& Deshpande, M. S. (2016). Job Satisfaction among Hospital Employees: A Review of Literature, 18(6), 27-31. http://doi.org/10.9790/487X1806032731

Mullins.L.J. (2005). Management and Organisational Behaviour. Book.

Myriam Breau, A. R. (2014). Relationships between empowerment, work environment on job satisfaction, intent to leave, and quality of care among...Dynamics, $25(3)$ 1624.Retrievedfromhttps://www.resea rchgate.net/profile/Myriam_Breau/pu blication/272883906_Relationships_b etween_empowerment_work_environ ment_on_job_satisfaction_intent_to_1 eave_and_quality_of_care_among_IC U_nurses/links/54f1e1 f90cf2b36214a ce-30f.pdf\%5Cnpapers3://publication
Scull, T. M.(2010). Adolescents' Mediarelated Cognitions and Substance Use in the Context of Parental and Peer Influences. J Youth Adolesc 39(9): 981-998, 39. 